Jurnal Ilmu Sosial dan Pendidikan (JISIP)

Vol. 5 No. 3 Juli 2021

Terakreditasi Peringkat 5 (No. SK: 85/M/KPT/2020)

e-ISSN : 2656-6753, p-ISSN: 2598-9944

DOI: 10.36312/jisip.v5i3.2076/http://ejournal.mandalanursa.org/index.php/JISIP/index

\title{
Meneropong Nilai Religius Islam dan Nilai Moral dalam Tradisi Begalan yang Berkembang di Karesidenan Banyumas
}

\author{
${ }^{1}$ Mustofa Kamaludin, ${ }^{2}$ Abdul Wachid BS \\ ${ }^{1}$ Pasca Sarjana PGMI, IAIN Purwokerto \\ ${ }^{2}$ IAIN Purwokerto
}

Email: ${ }^{1}$ mustofakamaludin77@gmail.com, ${ }^{2}$ abdulwachidbs@iainpurwokerto.ac.id

\author{
Article Info \\ Article history: \\ Article Accepted: May 212021 \\ Publication : July 042021
}

Keywords:
religious values, moral
values, Begalan, Banyumas

Article Info
Article history:
Article Accepted: May 212021
Publication : July 042021

Keywords:

Nilai Religi, Nilai Moral, Begalan, Banyumas.

\begin{abstract}
The Banyumasan Begalan traditional ceremony is a form of ritual as well as a performing arts entertainment media in the form of drama because there is an element of dialogue in it. From the time sequence of the performances, the utterances, and the tools carried in Begalan have a moral meaning and Islamic religious values in relation to the formation of a Muslim family, namely the realization of the sakinah family, mawadah wa rahmah. Therefore, the Banyumas Begalan traditional ceremony is very suitable as a source of character education in schools and the meaning contained in it can be used as a reference for prospective brides in pre-marriage courses or what we have been managing with Suscatin (Candidate Bride Course). This study aims to describe: (1) the procession of the Begalan tradition, (2) the public's perception of the symbolic meaning, (3) a review of Islamic law and, (4) the function of Begalan. This research is descriptive qualitative. The data collection technique in this research is observation through secondary data, namely in the form of youtube videos, and document review. The object of this research is religious values and moral values in the Begalan traditional ceremony in the former Banyumasan Residency.
\end{abstract}

Corresponding Author:

Mustofa Kamaludin

Pasca Sarjana PGMI, IAIN Purwokerto

Email: mustofakamaludin77@gmail.com 


\section{PENDAHULUAN}

Sebagai bagian dari sebuah budaya , upacara adat Begalan yang berkembang di wilayah eks Karesidenan Banyumas meliputi Kabupaten Purbalingga, Kabupaten Banyumas, Kabupaten Cilacap dan Kabupaten Banjarnegara perlu dilestarikan dan diperkenalkan kepada generasi muda agar tidak tergerus zaman. Menurut Ruli Nasruloh (2018:15) budaya pada dasarnya merupakan nilai-nilai yang timbul dari proses hubungan antar-individu. Nilai-nilai ini diakui, baik secara langsung maupun tidak, seiring dengan waktu yang dilalui

dalam hubungan tersebut. Bahkan kadang nilai tersebut berada di dalam alam bawah sadar individu dan diwariskan kepada generasi berikutnya.

Menurut hemat penulis, lahirnya upacara adat Begalan terdapat beberapa versi. Namun yang banyak tertulis dalam sejarah Banyumas menyebutkan upacara adat Begalan sudah ada sejak Adipati Wirasaba yang saat itu menikahkan putranya Dewi Sukesi dengan putra sulung Adipati Banyumas yaitu Pangeran Tirtakencana. (Disbudpar Banyumas, 2009: 29-30).

Terdapat nilai religi Islam yang terkadung dalam tradisi Upacara adat Begalan. Menurut Renggo Astuti, dkk (1998: 71 ) yang dimaksud dengan nilai religius adalah nilai-nilai berkaitan dengan keagamaan, keimanan dan respon individu terhadap nilai-nilai yang dianut dan perbuatan manusia sebagi wujud keimanan kepada Tuhan Yang Maha Esa.

Adapun nilai religi Islam tersebut terkandung dalam perlengkapan dan peralatan yang dibawa pada upacara adat Begalan yaitu tentang nilai filosofi yang muaranya untuk pembentukan keluarga sakinah, mawadah dan wa rahmah sebagai tujuan akhir dari perkawinan keluarga muslim.

Adapun makna simbolik ditunjukkan dalam properti, seperti ian, ilir, kukus, layah, pedaringan, muthu, irus, siwur, nasi, , sapu, wangkring, suket, cething, daun salam, dan seni tampah Begalan dapat memberikan pendidikan nilai agama bagi masyarakat muslim Banyumas yaitu tentang konsep tujuan nikah dalam Islam yaitu terbentuknya keluarga sakinah, mawadah, wa rahmah sebagai wujud keimanan kepada Tuhan Yang Maha Esa.

Sebagai seni tradisi yang berupa pertunjukan drama terdapat nilai moral yang bisa dipetik dari upacara tradisi Begalan. Menurut Harry Sulastianto ,dkk ( 2007: 181) :

Dalam pertunjukan drama terdapat nilai-nilai moral yang merupakan misi pengarang untuk dikomunikasikan pada publik. Nilai-nilai moral yang bersifat sastrawi kemudian diterjemahkan ke dalam bahasa pertunjukan oleh penggarap drama, maka terjadilah transformasi. Sejauh mana tingkat kesesuainnya ? Naskah drama tidak selamanya bisa sesuai persis dengan garapannya. Keindahan membaca karya sastra drama berbeda dengan keindahan menonton suara drama yang dipentaskan. Dengan demikian, sastra drama yang dipentaskan bisa lebih indah atau lebih buruk dari aslinya. Disamping itu, jika nilai-nilai moral tadi dibandingkan dengan realitas hidup, apakah sesuai, bertolak belakang atau melanggar tata moral yang berlaku dalam kehidupan sehari-hari .

\section{METODE PENELITIAN}

Jenis penelitian yang digunakan penulis adalah penelitian kualitatif deskriptif. Menurut Suharsimi Arikunto (2014: 21-22) agar penelitian berkualitas maka data yang dikumpulkan seyogyanya lengkap yaitu data primer dan data sekunder. Data primer adalah data berupa katakata verbal atau lisan, gerak tubuh atau perilaku yang dilakukan oleh subjek yang dapat diandalkan, dalam hal ini subjek penelitian (informan) berkenaan dengan variabel yang diteliti. Data sekunder adalah data yang diperoleh dari dokumen grafik (tabel, catatan, notulen rapat, SMS, dll), foto, film, rekaman video, objek dan lain-lain yang dapat memperkaya data primer.

Tujuan penelitian deskriptif kualitatif adalah untuk memperoleh gambaran tentang kualitas objek kajian yang berbentuk tradisi. Waktu penelitian ini dilakukan selama satu bulan yaitu mulai bulan November sampai dengan Desember 2020. Dalam hal ini penulis mengamati video YouTube tentang tradisi Begalan. Alasan penulis menggunakan data sekunder melalui tayangan video YouTube karena pada saat penelitian ini dilakukan pada saat terjadi pandemi 
Covid-19 sehingga acara yang berkaitan dengan hajatan pengantin sangat jarang dilakukan oleh masyarakat eks Karesidenan Banyumas.

Teknik pengumpulan data yang digunakan adalah observasi, wawancara, dan dokumentasi. Untuk metode wawancara, penulis menggunakan aplikasi whaatsapp untuk memperoleh informasi dan data. Teknik keabsahan data yang digunakan yaitu triangulasi sumber analisis data dalam penelitian ini dilakukan dengan menggunakan tiga komponen yaitu reduksi data, penyajian data, dan simpulan atau verifikasi. Pekerjaan analisis data dalam hal ini adalah meringkas data, menyederhanakan serta menyimpulkan data dengan alur penelitian yang digunakan.

\section{HASIL DAN PEMBAHASAN}

Hasil analisis dalam penelitian ini terdapat empat pembahasan yaitu prosesi tradisi Begalan, persepsi masyarakat terhadap makna simbolik, tinjauan hukum Islam dan fungsi Begalan.

\subsection{Prosesi pelaksanaan Begalan}

Mengenai proses pelaksanaan Begalan yang penulis amati dalam tayangan youtube penelitian yang peneliti lakukan menjelaskan bahwa terdapat dua tahap dalam prosesi Begalan, yaitu tahap persiapan dan tahap pelaksanaan.

\subsubsection{Tahap Persiapan}

Tahap persiapan yang dilakukan adalah: pertama, menyiapkan peralatan yang akan digunakan dalam pertunjukan. Peralatan (Ubarampe) dalam tradisi Begalan disediakan oleh tuan rumah yang mempunyai hajat. . Persiapan yang dilakukan selaku pemain Begalan yaitu merias wajah dan menyiapkan kostum serta perlengkapan yang akan digunakan. Tata rias yang digunakan oleh pemain Begalan ini sangat sederhana, disesuaikan dengan karakter tokoh yang dimainkan.

Menurut hemat penulis tradisi Begalan lebih condong ke seni drama karena terdapat dialog dan pemeranan tokoh. Usul Wiyanto ( 2002: 4) menggambarkan seni drama sebagai berikut : "Seni drama diwujudkan dari berbagai bahan dasar karena dalam seni drama terkandung seni-seni yang lain. Seni drama sebagai tontonan merupakan perpaduan sejumlah cabang seni, yaitu :

1) seni sastra ( naskah cerita ),

2) seni lukis ( tata rias dan tata panggung),

3) seni musik (musik pengiring ),

4) seni tari ( gerak-gerik pemain), dan

5) seni peran ( pemeranan tokoh).

Kelima unsur tersebut melekat pada seni tradisi Begalan, hanya saja dalam jumlah yang sedikit untuk masing masing bagian.

\subsubsection{Tahap Pelaksanaan}

Tradisi Begalan tidak membutuhkan panggung, cukup di halaman rumah pengantin wanita. Gerakan tari tradisional Begalan tidak terikat oleh aturan tertentu seperti tari klasik. Setelah semua persiapan selesai, acara Begalan pun siap dimulai. Permainan Begalan ini diiringi oleh gendhing Banyumasan. Gerakan tarian tidak terikat oleh aturan tertentu seperti tarian klasik. Pemain Begalan yang mewakili pengantin pria disebut Surantani. Sebelum memasuki pelataran rumah mempelai wanita, rombongan mempelai pria berjajar mulai dari Surantani, penari cucuk lampah, mempelai pria yang didampingi oleh orang tuanya dan para pengiring pengantin. 


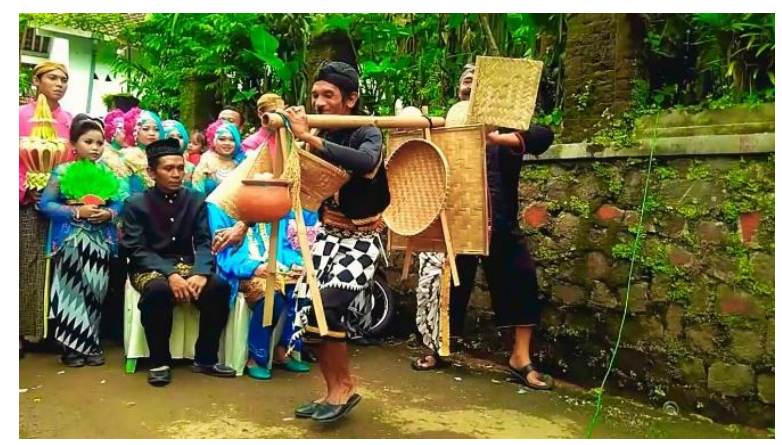

Gambar 1. Tradisi Begalan yang berkembambang di Wilayah Banyumas

Eka Desy Budiastuti dalam artikelnya menggambarkan tradisi Begalan sebagai berikut:

Diiringi gendhing khas Banyumasan, para aktor Begalan menampilkan dialek dan pesan moral yang diselingi dengan canda, sindiran, serta nasehat kepada penonton. Gendhing yang dipilih biasanya bernada dinamis dan suasana ceria. Secara umum proses pelaksanaan Begalan merupakan tradisi yang baik karena mengandung nasehat bagi kedua mempelai dan masyarakat Banyumas yang tertuang dalam lambanglambang alat-alat rumah tangga. Namun dalam pelaksanaannya di penghujung prosesi tradisi Begalan, barang-barang yang dibawa oleh juru bahasa Begal menjadi rusak atau pecah sehingga menjadi mubazir. Perkakas (ubarampe) yang digunakan dalam tradisi Begalan memiliki makna simbolis yang berguna bagi kehidupan masyarakat.

Salah satu ubarampe yang digunakan adalah kukusan yaitu alat penanak nasi yang terbuat dari anyaman bambu berbentuk kerucut. Makna simbolisnya, seseorang yang telah berani hidup berumah tangga harus berani berjuang untuk memenuhi kebutuhannya meskipun ia harus merasakan sesuatu yang tidak menyenangkan atau kurang diinginkan. (Vol. / 06 / No. 02 / April 2015)

Saat rombongan mempelai pria sampai di halaman rumah mempelai wanita, pihak mempelai pria dan keluarganya tidak langsung masuk ke rumah wanita tersebut. Rombongan mempelai pria dicegat oleh perwakilan mempelai wanita bernama Suradenta. Suradenta memberi syarat kepada Surantani bahwa dia bisa masuk jika Surantani bisa menjelaskan arti semua barang yang dibawa. Surantani menyetujui persyaratan tersebut.

Ada dialog di antara keduanya. Setelah semua selesai, kendhil tersebut dipecahkan oleh Suradenta sebagai tanda bahwa pembatas atau bahaya telah disingkirkan. Di penghujung pertunjukan Begalan, barang-barang yang dibawakan Surantani disambar penonton. Mereka yakin, jika barang yang diperebutkan tersebut bisa membawa berkah bagi yang mendapatkannya.

\subsection{Persepsi Masyarakat terhadap makna simbolik Begalan}

Onan Marakli Siregar, dkk dalam (2020 : 11) mengatakan bahwa secara etimologis persepsi atau dalam bahasa inggris perception berasal dari bahasa latin perceptio; dari percipere, yang artinya menerima atau mengambil.

Sedangkan yang di maksud makna simbolik adalah arti dan hikmah yang terkandung dalam simbol - simbol yang dipakai pada perangkat upacara yang telah ditentukan (Departemen Pendidikan dan Kebudayaan, 1992 : 5). Adapun makna Simbolik yang terdapat pada perlengkapan yang dibawa pada tradisi Begalan terdapat pada tabel berikut :

Tabel 1. Makna simbolik dari perlengkapan yang dibawa pada tradisi Begalan

\begin{tabular}{|c|c|l|}
\hline No & Perlengkapan & \multicolumn{1}{c|}{ Makna Simbolik } \\
\hline 1 & Iyan & Tempat berpijak \\
\hline 2 & Ilir & Agar dapat membedakan perbuatan baik dan buruk \\
\hline 3 & Kukusan & $\begin{array}{l}\text { Yang sudah berumah tangga harus mencukupi kebutuhan hidup } \\
\text { keluarganya }\end{array}$ \\
\hline
\end{tabular}




\begin{tabular}{|c|c|l|}
\hline 4 & Centhong & $\begin{array}{l}\text { Menggambarkan Kedua mempelai wajib mencari rejeki, } \\
\text { bagaimanapun usaha yang dilakukan yang penting halal dan } \\
\text { bisa mencukupi kebutuhan rumah tangga }\end{array}$ \\
\hline 5 & Irus & $\begin{array}{l}\text { Menggambarkan baik suami maupun isteri wajib berusaha } \\
\text { untuk memenuhi kehidupan rumah tangga }\end{array}$ \\
\hline 6 & Siwur & $\begin{array}{l}\text { Kedua mempelai juga wajib mencari ilmu kepada yang sudah } \\
\text { berpengalaman agar dalam mengarungi bahtera rumah tangga }\end{array}$ \\
\hline 7 & Wangkring & $\begin{array}{l}\text { Kesepakatan kedua belah pihak dalam menentukan hari } \\
\text { pernikahan }\end{array}$ \\
\hline 8 & Muthu & Suami mampu memberikan contoh yang baik untuk keluarganya \\
\hline 9 & Ciri & Suami isteri harus bisa saling mengingatkan \\
\hline 10 & Pari & Ketika sudah menikah harus memikirkan kebutuhan keluarga \\
\hline 11 & Kendhil & Seorang istri harus bisa mengatur keuangan \\
\hline 12 & Godhong salam & $\begin{array}{l}\text { Menggambarkan kedua mempelai yang meminta keselamatan } \\
\text { kepada Allah Swt agar pernikahannya selamat dunia akhirat. }\end{array}$ \\
\hline
\end{tabular}

\subsection{Tinjauan hukum Islam terhadap tradisi Begalan}

Adapun dalam pandangan Islam tentang tradisi Begalan, diperbolehkan jika unsur kemubaziran dihilangkan. Tradisi Begalan perlu ditinjau ulang karena Begalan merupakan tradisi nasehat yang mengandung nilai-nilai keislaman dan kepercayaan masyarakat Banyumas terhadap Begalan sebagai tradisi menolak bala itu tidak berdasar dan terbukti. Hanya hasil pemikiran masyarakat yang dijadikan keyakinan dan cara hidup. Selain berfungsi sebagai hiburan dan pelestarian budaya secara turun-temurun.

Apabila tradisi upacara Begalan itu dikaitkan dengan penolak bala jelas bertentangan dengan pandangan Islam. Secara etimologis tolak bala terambil dari bahasa Arab yakni bala yang berarti bencana . Hermansyah, dkk (2006: 52) mengatakan bahwa: ' Tolak bala terambil dari sebuah doa yakni doa tolak bala yang dimaksudkan untuk menolak kesialan , ketidakberuntungan, menolak bencana .

Menurut pandangan Islam apabila meyakini benda - benda tertentu itu dapat menentukan nasib rumah tangga seseorang bisa dikategorikan sebagai perbuatan syirik. Pikiran dan keyakinan yang mengarah pada syirik harus ditolak dengan tegas agar masyarakat sadar bahwa keyakinan masyarakat itu salah. Ada juga ayat Al-Qur'an yang menjelaskan bahwa perbuatan yang mengarah pada syirik adalah dosa besar.

Menurut hemat penulis benda-benda yang dibawa dalam tradisi Begalan bukan untuk diyakini kekuatannya sebagai wahana penolak bala tetapi untuk diambil makna filosifisnya. Sebagaimana kita ketahui masyarakat Banyumas yang merupakan bagian dari masyarakat Jawa masih memiliki tradisi yang kuat untuk mengambil makna dari sebuah benda. Sindung Haryanto (2013 : v ) mengatakan bahwa :

Budaya ]awa sangat kaya akan simbol-simbol. Masing-masing simbol dapat memiliki yang berbeda bahkan mungkin bertentangan. Hal ini wajar karena makna suatu simbol lebih merupakan hasil interpretasi ukan merupakan ketetapan (stipulation). Suatu simbol tercipta bukan merupakan suatu kebetulan melainkan melalui proses perenungan yang panjang dengan maksud dapat menjadi pedoman tingkah laku ( code of conduct). Oleh karena itu pemahaman terhadap simbol- simbol dapat menjadi "pintu gerbang" terciptanya harmoni dan tatanan masyarakat yang lebih baik sesuai dengan sesanti orang Jawa yakni memayu hayuning bawono, mangasah mingising budi, memasuh, malaning bumi.

Sebagai contoh : Godhong salam (daun salam), menggambarkan kedua mempelai yang meminta keselamatan kepada Allah Swt agar pernikahannya selamat dunia akhirat. Jadi daun salam yang dibawa bukan sebagai wahana tolak bala akan tetapi memiliki makna agar selamat di dunia dan akhirat.

Apabila dikaitkan dengan sisi budaya penulis berpendapat bahwa Begalan merupakan salah satu seni tradisi khas Banyumasan yang populer di samping kenthongan atau tek-tek 
Banyumasan, Ebeg (Kuda Lumping), Calung, Lengger, dan kesenian lainnya yang menjadi daya tarik masyarakat karena keunikan dan kejenakaannya.

Sigit Purnomo Adi,dkk (--- :4) menggarisbawahi bahwa: "Seni tradisi adalah seni yang stereotip, taat azaz, memegang teguh pakem atau ketentuan yang ada sehingga kreativitas hampir-hampir tidak diperlukan, sedang sementara itu seni kontemporer adalah seni yang haus akan perubahan, yang amat menghargai kreasi dan inovasi”.

Tradisi Begalan selalu ditampilkan dalam suasana yang ramai, ketika seseorang mengadakan akad nikah, tradisi ini sangat lekat dengan sejarah Banyumas. Begalan merupakan salah satu bentuk ritual yang sangat penting dalam upacara pernikahan di Banyumas karena selain berfungsi sebagai sarana penolak bala, terdapat nilai dakwah, nilai edukatif, dan nilai sosial yang diperuntukkan bagi mempelai wanita. dan pengantin pria dan orang lain yang hadir pada upacara tersebut. Begalan sendiri memiliki tradisi unik karena hanya ada di Banyumas. Dalam pandangan sebagian orang, tradisi ini dipandang menyimpang dari ajaran Islam. Hal ini karena pada zaman dahulu tradisi ini melakukan ritual yang disinyalir tidak berdasarkan ajaran Islam karena fungsinya sebagai sarana slametan. Peralatan dan perkakas dalam begalan memiliki arti dan makna yang penting melalui simbol-simbol yang diharapkan dapat dijalankan dan dihayati oleh masyarakat Banyumas. Dalam prosesi Begalan yang dimaknai sebagai tempat pemujaan mengingatkan kita pada Dewi Sri yang dipahami oleh masyarakat Jawa khususnya Banyumas sebagai simbol kesuburan. Dalam perkembangannya, apalagi dewasa ini, makna lambang beras dalam tradisi begalan diubah maknanya menjadi sifat manusia, harus meniru karakter padi yang semakin tua semakin merunduk.

\subsection{Fungsi Pelaksanaan Tradisi Begalan}

Tradisi Begalan sudah berlangsung puluhan tahun dan dijadikan rutinitas dalam pernikahan. Hal tersebut dikarenakan tradisi ini mempunyai nilai positif dan berpengaruh besar bagi kehidupan berumah tangga sepasang suami istri, khususnya bagi masyarakat eks Karesidenan Bnayumas. Selain itu juga sebagai rasa hormat dan menghargai warisan budaya dari nenek moyang.

Tradisi mengandung fungsi antara lain:

1. Untuk mempertebal rasa solidaritas masyarakat

Tak bisa dipungkiri bahawa tradisi Begalan yang berkembang di wilayah eks Karesidenan Banyumas itu hanya tumbuh susbur di daerah daerah pedesaan yang masih memegang rasa solidaritas, gotong royong dan semangat memupuk persatuan dan kesatuan. Bisa kita lihat apabila sebuah hajatan di lingkungan pedesaaan maka sudah bisa dipastikan para tetangga akan bergotong royong membantu sang punya hajat. Hal ini merupakan tradisi yang masih kental sampai sekarang. Kehadiran wedding organizer hanya sebatas untuk melakukan kegiatan yang tidak dapat ditangani oleh para tetangga dan memang butuh keahlian khusus.

2. Sebagai alat yang menyenangkan dan memberi hiburan

Persembahan berupa karya seni Begalan yang banyak memiliki makna filosofi itu dipercaya akan menjadikan doa-doa yang ditujukan kepada Sang Pencipta akan didengar dan dengan demikian pula kelestarian hidup umat manusia akan tetap terjamin. Tindakan persembahan seperti itu bukanlah hubungan ritual manusia dengan Tuhan. Akan tetapi di dalamnya ada unsur-unsur tertentu yang bersifat menghibur.

\section{KESIMPULAN}

Makna filosofis yang terkandung dalam benda-benda yang dibawa dalam tradisi ini sejalan dengan konsep tujuan pernikahan muslim, yaitu terbentuknya keluarga sakinah yang merupakan keinginan, harapan bahkan tujuan membangun rumah tangga. Sakinah sendiri artinya ketenangan. Jika dikaitkan dengan keluarga, itu berarti keluarga yang tenang, tenteram, dan damai. Ikatan perkawinan bukan hanya untuk pemenuhan materi dan biologis. Pemenuhan kebutuhan material seperti pangan, sandang, papan dan lain-lain, hanyalah sarana pemenuhan 
kebutuhan yang lebih tinggi yaitu kebutuhan spiritual, cinta, kasih sayang dan berkah dari Allah SWT.

Dilihat dari sudut pandang nilai moral, makna filosofis perlengkapan dan peralatan yang dibawa pada tradisi Begalan juga sejalan dengan prinsip moral manusia . tidak hanya dalam hubungannya dengan rumah tangga akan tetapi bisa diterapkan dalam kancah yang lebih luas, diantaranya : suka bekerja keras, saling menghormati, setia, suka bermusyawarah, tidak egois dan sebagainya.

\section{SARAN} adalah:

Penulis memberi beberapa saran berkenaan dengan seni tradisi Begalan, diantarannya

1. Nilai- nilai religi yang terkandung dalam budaya Begalan bisa dijadikan rujukan oleh pejabat Kantor Urusan Agama (KUA) untuk menjadi bahan ajar pada Kursus Calon Pengantin (Suscatin).

2. Nilai-nilai pendidikan moral yang terkandung dalam makna simbolis properti (peralatan) tradisi Begalan dapat diterapkan dalam kehidupan masyarakat di eks Karesidenan Banyumas.

3. Agar pemerintah Kabupaten yang ada di eks Karesidenan Banyumas yang meliputi Kabupaten Purbalingga, Kabupaten Banyumas, Kabupaten Cilacap dan Kabupaten Banjarnegara perlu membuat kebijakan untuk mengembangkan seni Begalan menjadi tontonan dan ditampilkan dalam panggung lewat instansi Dinas Pendidikan Pemuda dan Olahraga.

4. Seni Begalan dapat dimasukkan sebagai materi subjek seni dan budaya di sekolah, khususnya di eks Karesidenan Banyumas

\section{DAFTAR PUSTAKA}

Astuti, Renggo , dkk . 1998. Kajian Nilai Budaya Naskah Kuna Kakawin Aji Palayon. Jakarta : Departemen Pendidkan dan Kebudayaan

Arikunto, Suharsimi.. (2014). Prosedur Penelitian Suatu Pendekatan Praktik, Jakarta: Rineka Cipta

Eka Desy Budiastuti, (2015) . Persepsi Masyarakat Terhadap Makna Simbolik dan Tinjauan Hukum Islam dalam Tradisi Begalan di Desa Karangsalam Kecamatan Kemranjen Kabupaten Banyumas. Jurnal Program Studi Pendidikan Bahasa dan Sastra Jawa Universitas Muhammadiyah Purworejo . Vol. / 06 / No. 02 / April 2015. http://ejournal.umpwr.ac.id/index.php/aditya/article/view/2113

Haryanto,Sindung,.(2013). Dunia Simbol Orang Jawa. Yogyakarta : Kepel Press

Hermansyah, dkk ,. (2006). Dakwah Islam di Kalimantan Barat . Pontianak : STAIN Pontianak Press

Marakli Siregar ,Onan, dkk,. (2020) Persepsi Masyarakat terhadap Bank Syariah. Medan : Puspantara

Nasrullah, Rulli,.(2018). Komunikasi Antar Budaya: di Era Budaya Siber. Jakarta : Prenada Media

Pemerintah Kabupaten Banyumas Dinas Kebudayaan dan Pariwisata kabupaten Banyumas. 2009. Himpunan Cerita dan Legenda Rakyat Banyumas. Banyumas

Purnomo Adi,Sigit ,dkk,.(----) . Perkembangan Seni Urban di Surakarta. :Dwi-Quantum

Sulastianto, Harry ,dkk. 2007. Seni Budaya. Jakarta: Grafindo Media Pratama

(1992). Perangkat/alat-alat dan pakaian serta Makna Simbolis Upacara Keagamaan di lingkungan Keraton Yogyakarta. Yogyakarta : Departemen Pendidkan dan Kebudayaan

Wiyanto,Usul,. (2002). Terampil Bermain Drama. Jakarta : Grasindo 